\title{
Role of IP-10 during follow up of pulmonary tuberculosis patients
}

\author{
Himanshu Saini ${ }^{1}$, Parul Mrigpuri², Balakrishnan Menon $^{2}$, Sonal Sonal ${ }^{2}$ \\ ${ }^{1}$ Department of Pulmonary Medicine, Max Superspeciality hospital, Saket, New Delhi; ${ }^{2}$ Department of Pulmonary \\ Medicine, Vallabhbhai Patel Chest Institute, University of Delhi, New Delhi, India
}

\begin{abstract}
Pulmonary tuberculosis (PTB) is an infectious disease caused by Mycobacterium tuberculosis (MTB) and is associated with significant mortality and morbidity. There has been a number of advances in the diagnosis of PTB but there is a need for simple blood based diagnostic test. A follow up of the patients on treatment remains challenging. This study was planned to evaluate the role of IP-10 in the follow up of PTB patients. A total of 60 subjects were enrolled in the study, 40 patients with confirmed diagnosis of PTB and 20 healthy controls. The value of interferon
\end{abstract}

Correspondence: Dr Parul Mrigpuri, Assistant Professor, Department of Pulmonary Medicine, Vallabhbhai Patel Chest Institute, Room No. 22, OPD Block, Delhi 110007, India.

Mobile+91.8826687316. E-mail: parul57_mrigpuri@yahoo.com

Keywords: Pulmonary tuberculosis; IP-10; follow up.

Author contributions: All authors have contributed to this manuscript and have approved the final version in agreement to be accountable for all aspects of work.

Conflicting Interest: The authors have no conflict of interest to declare.

Ethics approval and consent to participate: This study has been approved by the Ethical Committee of the Institute. Written consent to participate were obtained from all study participants.

Patient consent for publication: A written informed consent from the patients was obtained.

Received for publication: 20 July 2021.

Accepted for publication: 21 December 2022.

Publisher's note: All claims expressed in this article are solely those of the authors and do not necessarily represent those of their affiliated organizations, or those of the publisher, the editors and the reviewers. Any product that may be evaluated in this article or claim that may be made by its manufacturer is not guaranteed or endorsed by the publisher.

${ }^{\text {CC}}$ Copyright: the Author(s), 2022

Licensee PAGEPress, Italy

Monaldi Archives for Chest Disease 2022; 92:2022

doi: 10.4081/monaldi.2022.2022

This article is distributed under the terms of the Creative Commons Attribution-NonCommercial International License (CC BY-NC 4.0) which permits any noncommercial use, distribution, and reproduction in any medium, provided the original author(s) and source are credited.
(IFN) $\gamma$ inducible protein 10 (IP10) was measured in all the subjects at the start of the treatment and at a follow up of two months. Mean age of the study subjects was 40.96 years. Mean duration of symptoms at presentation was 1 month and 17 days. The induration on Tuberculin skin test (TST) was between 10-20 mm in most $(62.5 \%)$ of the study subjects. Majority (45\%) showed moderately advanced disease on chest x-ray. There was no association of IP10 with TST diameter and gene x-pert. Similarly, no significant difference in IP-10 levels was found in relation to sputum grading and $\mathrm{x}$-ray score at diagnosis and after 2 months of treatment. IP10 has very limited role in diagnosis of active TB in especially in high TB burden countries. The role of IP-10 in follow up of PTB patients could not be ascertained by our study. However, more studies are needed in this pretext with larger sample size and extended duration of follow up.

\section{Introduction}

Tuberculosis (TB) infects about 10 million people and is responsible for 1.2 million deaths around the globe [1]. Mycobacterium tuberculosis (MTB) is an aerobic, gram-positive bacilli with a very slow generation time of 16-20 hours thus imposing diagnostic difficulties [2]. In the recent years there have been developments in the diagnosis of Tuberculosis in the form of molecular methods of diagnosis like Gene X-pert however, culture remains the gold standard for diagnosis requiring large amount of time [3]. Follow up of the patients on treatment still remains challenging with the use of time-consuming culture-based methods. There is a requirement for the rapid, reliable, and simple bloodbased test for diagnosing TB and further there is also the need for a prognostic marker for evaluation of treatment response in PTB as molecular methods cannot be used for this purpose. Biomarkers for Tuberculosis continue to be an active area of research and multiple biomarkers have been evaluated for diagnosis of TB. The interferon (IFN) $\gamma$ inducible protein 10 (IP10) is produced by monocytes/macrophages. It interacts with a CXC chemokine receptor and helps in trafficking T helper type 1 (Th1) lymphocytes to inflamed foci. Various studies have evaluated the diagnostic role of IP10 in TB with variable results [4-6]. In our study we attempted to evaluate the role of IP-10 in the follow up of PTB patients.

\section{Materials and Methods}

This was case control, prospective study. A total of 60 subjects were enrolled in the study, 40 patients with confirmed diagnosis of PTB (sputum smear positive for acid fast bacilli (AFB), culture positive or quality assured rapid diagnostic molecular 
test-based diagnosis or histopathological proven tuberculosis) and diagnosed for first time with tuberculosis. Also, 20 healthy controls were recruited after taking a written informed consent. Pregnant and lactating female and patients with any systemic disease such as hypertension, diabetes mellitus, hepatic disease, renal disease, and HIV positive patients were not recruited. Chest $\mathrm{X}$-ray and clinical examination was performed on all participants. Tuberculin skin test was done, and sputum sample was obtained for acid fast staining and Gene X-pert in PTB suspects. The patients diagnosed with active TB were given standard antiTB chemotherapy according to National guidelines [7]. The value IP-10 was measured in all the subjects at the start of the treatment and at a follow up of two months. The IP-10 levels were measured by sandwich-type enzyme-linked immunosorbent assay technique using IP-10 antibody kit as per the manufacturer's instructions and its levels were expressed in picograms per milliliter (pg/ml). The Ethics Committee Approval for the study was obtained from the Ethical Committee of the Institute.

Sample size was determined using the sample size for paired $t$ test assuming the anticipated population standard deviation of the outcome variable i.e., IP-10 values of $4.40 \mathrm{pg} / \mathrm{ml}$, clinically significant difference of $2 \mathrm{pg} / \mathrm{ml}$ at $5 \%$ level of significant and $80 \%$ power. Sample size was found to be 40 .
The quantitative variables were analyzed by mean $+/-$ $\mathrm{SD}(\mathrm{SEM})$ as applicable, median and inter quartile range. All parameters were tested for normalcy. If found normal, $t$ test was applied, otherwise Wisconsin test range was used. Significance was accepted if $\mathrm{P}$ - value was $<0.05$. The analysis was done using $\mathrm{R}$ software version 3.5.1.

\section{Results}

The study examined 40 PTB patients and 20 healthy controls. Table 1 shows the demographic, clinical and radiological characteristics of the study subjects. All the controls were asymptomatic and had normal chest X-ray. Among symptoms, cough (100\%) and sputum production $(97.5 \%)$ were the most common symptom, followed by fever $(82.5 \%)$, decreased appetite $(72.5 \%)$, weight loss (72.5\%), exertional breathlessness (12.5\%), hemoptysis $(12.5 \%)$, and chest pain $(22.5 \%)$. Table 2 shows the values of IP-10 in cases and controls at diagnosis. The mean value of IP-10 at the time of diagnosis was $30.04 \pm 13.09 \mathrm{pg} / \mathrm{ml}$ whereas, the mean value after 2 months was $32.54 \pm 16.74$ (Table 3). On applying independent $t$-test to analyze the values of IP-10 at initiation of treatment and after 2

Table 1. Demographic, clinical and radiological characteristics of the cases.

\begin{tabular}{|c|c|c|}
\hline Characteristic & Cases $(n=40)$ & Controls $(n=20)$ \\
\hline Mean age & 40.96 years & 35.89 years \\
\hline Gender (male/female) & $35 / 5$ & $14 / 6$ \\
\hline Mean duration of symptoms & 1 month 17 days & - \\
\hline Tuberculin skin test & n $(\%)$ & \\
\hline $10-20 \mathrm{~mm}$ & $25(62.5 \%)$ & \\
\hline $20-30 \mathrm{~mm}$ & $12(20 \%)$ & \\
\hline$>30 \mathrm{~mm}$ & $3(7.5 \%)$ & \\
\hline Sputum for AFB & n $(\%)$ & \\
\hline $\begin{array}{l}\text { Negative } \\
1+ \\
2+ \\
3+\end{array}$ & $\begin{array}{c}15(37.5 \%) \\
16(40 \%) \\
7(17.5 \%) \\
2(5 \%)\end{array}$ & \\
\hline GeneXpert & n (\%) & \\
\hline MTB not detected & $5(12.5 \%)$ & \\
\hline MTB detected very low & $15(37.5 \%)$ & \\
\hline MTB detected low & $8(20 \%)$ & \\
\hline MTB detected medium & $7(17.5 \%)$ & \\
\hline MTB detected high & $5(12.5 \%)$ & \\
\hline Rifampicin resistance & Nil & \\
\hline Chest X-ray (according to National Tuberculosis and Respiratory Disease Association of USA) & $\mathrm{n}(\%)$ & \\
\hline Minimal disease & $17(42.5 \%)$ & \\
\hline Moderately advanced & $18(45 \%)$ & \\
\hline Far advanced & $7(17.5 \%)$ & \\
\hline
\end{tabular}

Table 2. Mean values of IP-10 in cases (at time of diagnoses) and controls.

\begin{tabular}{lcccc} 
IP-10 values & N & Mean & P \\
Cases & 40 & 30.04 & \pm 13.09 & 0.394 \\
Controls & 20 & 27.21 & \pm 12.26 \\
\hline
\end{tabular}


months of treatment, it was statistically insignificant with $\mathrm{p}>0.05$ and $95 \%$ confidence lower limit at -15.67 and upper limit at 18.218. Possible co-relation of IP-10 with the clinical and radiological parameters was investigated. Tuberculin skin test diameter and mean value of IP-10 increased simultaneously but it was statistically insignificant $(\mathrm{p}=0.991)$. Also, there was no association of IP-10 with GeneXpert. Similarly, no significant difference in IP-10 levels was found in relation to sputum grading and $\mathrm{X}$-ray score at diagnosis and after 2 months of treatment. Also, the area under ROC curve was found to be 0.572 which indicates that IP-10 is not a good diagnostic test for diagnosing pulmonary tuberculosis.

\section{Discussion}

Tuberculosis still remains among the top ten causes of death worldwide. A reduction in the incidence and deaths of TB requires improvement in access to diagnosis along with various other measures. This becomes even more important for high burden countries like India accounting for $27 \%$ of the global cases [1]. Various biomarkers like lipoarabinomannan (LAM), MTB Ag85 complex etc. have been evaluated for diagnosis and follow up of TB but yet there is lack of completely validated biomarker [2]. The World Health Organization recommended the use of lateral flow urine LAM assay for diagnosis of TB in human immunodeficiency virus (HIV) positive patients who have a cluster of differentiation (CD4) cell count less than or equal to 100 cells/ $\mu \mathrm{L}$ or who are seriously ill but strongly recommended against its use as a screening test for
TB [8]. IFN- $\gamma$ release assays (IGRAs) measure T-cell responses to MTB specific peptide antigens [9]. IFN- $\gamma$ IP-10 basically is a chemoattractant for activated T-cells and is produced by monocytes/macrophages and help to attract Th1 lymphocytes to sites of inflammation [10]. Lee et al. showed that IP-10 secretion from peripheral blood mononuclear cells significantly increased in PTB patients when stimulated with various mycobacterial antigens compared to the healthy tuberculin reactors [11]. Our study did not show significantly higher levels of IP-10 in PTB patients as compared to controls. This can be explained by the fact that India is a TB endemic country and latent tuberculosis infection (LTBI) was not ruled out in controls. Various studies have evaluated the role of IP-10 in diagnosis of active and latent TB suggesting comparable accuracy of IP-10 and Quantiferon-TB Gold In-Tube test (QFT-IT) in patients with active TB (Table 4). A systemic review and metaanalysis on accuracy of IFN- $\gamma$ IP-10 for diagnosing LTBI showed pooled sensitivity of 0.85 and specificity of 0.89 thus, indicating a good accuracy for diagnosing LTBI [12]. In another study Qiu et al. used meta-analysis approach to assess diagnostic value of IP-10 for PTB and showed a pooled sensitivity and specificity of IP-10 for PTB detection to be 86 and $88 \%$ respectively [13]. In another meta-analysis on diagnostic accuracy of IFN- $\gamma$ IP-10 for differentiating active tuberculosis from latent tuberculosis it was shown that overall pooled sensitivity and specificity was 0.72 and 0.83 respectively [14]. IFN- $\gamma$ IP-10 has also been studied in HIV positive patients as IGRA shows high rates of indeterminate due to low CD4 T-cell count in these patients [9]. In a study by Aabye et al. in HIV positive PTB patients it was found that IP-10 test performed with equal sensitivity to the QFT-IT and was less affected

Table 3. IP-10 values in cases at the time of diagnosis and after 2 months.

\begin{tabular}{|c|c|c|}
\hline & IP-10 at diagnosis $\mathrm{pg} / \mathrm{ml}$ & IP-10 after 2 months \\
\hline Mean & 30.04 & 32.54 \\
\hline Std. deviation & 13.09 & 16.74 \\
\hline Range & 63.4 & 63 \\
\hline Minimum & 9.0 & 15 \\
\hline Maximum & 72.6 & 78.0 \\
\hline p-value & & $>0.05$ \\
\hline
\end{tabular}

Table 4. Studies on the role of IP-10 in diagnosis of active and latent tuberculosis.

\begin{tabular}{|c|c|c|c|c|}
\hline \multirow[t]{2}{*}{ Authors } & \multirow{2}{*}{$\begin{array}{l}\text { Journal / year of } \\
\text { publication }\end{array}$} & \multicolumn{2}{|c|}{ Sample size } & \multirow[t]{2}{*}{ Results/Conclusions } \\
\hline & & Active TB & Latent TB & \\
\hline El-emiry et al. [4] & $\begin{array}{l}\text { Egyptian Journal of } \\
\text { Chest Diseases and } \\
\text { Tuberculosis / } 2015\end{array}$ & 20 & 20 & $\begin{array}{l}\text { IP-10 showed sensitivity } 88.9 \% \text { and specificity } 100 \% \text { indiagnosis } \\
\text { of active pulmonary and latent tuberculosis infection (LTBI). }\end{array}$ \\
\hline Hong et al. [5] & $\begin{array}{l}\text { International Journal of } \\
\text { Infectious Diseases / } 2012\end{array}$ & 46 & 22 & $\begin{array}{l}\text { IP-10 secretion significantly increased in both active TB and } \\
\text { LTBI subjects. }\end{array}$ \\
\hline Kabeer et al. [6] & Plos One / 2010 & 177 & & $\begin{array}{l}\text { QFT-IT and IP-10 were highly sensitive in detecting active TB } \\
\text { cases but had poor specificity. }\end{array}$ \\
\hline $\begin{array}{l}\text { Yoshihiro Kobashi } \\
\text { et al. [21] }\end{array}$ & $\begin{array}{l}\text { Mycobacterial } \\
\text { Diseases / } 2015\end{array}$ & 54 & & $\begin{array}{l}\text { IP-10 and monocyte induced IFN- using a supernatant } \\
\text { stimulated with MTB-specific antigens showed similar results } \\
\text { to IGRA. }\end{array}$ \\
\hline Jeong [22] & $\begin{array}{l}\text { Journal of Clinical } \\
\text { Microbiology / } 2014\end{array}$ & 33 & 20 & $\begin{array}{l}\text { Most patients showed higher IP-10 production to MTB } \\
\text { antigens than to mitogen and the ratio of TB-specific to } \\
\text { mitogen-induced responses for IP-10 was the strongest } \\
\text { indicator of active infection versus LTBI with } 93.9 \% \text { sensitivity } \\
\text { and } 90 \% \text { specificity. }\end{array}$ \\
\hline
\end{tabular}


by a low CD4 cell count than the QFT-IT [15]. Diagnostic efficacy of IP-10 has also been studied in children suggesting comparable diagnostic accuracy of IP-10 to QFT-IT but inability to distinguish between active TB and LTBI $[9,16,17]$.

However, very few studies have evaluated the role of IP-10 in follow up of PTB patients. Tonby et al. analyzed IP-10 levels from 34 patients with TB disease before and throughout 24 weeks of effective anti-TB chemotherapy, detected a significant decline of IP-10 levels starting at two weeks of therapy [18]. In another study ,Azzurri et al. evaluated the role of IFN- $\gamma$ IP-10 in monitoring inflammation and disease activity in PTB patients and found that IP-10 levels were significantly higher in untreated PTB patients and also showed significant reduction at the end of treatment [19]. One more study by Wergeland et al. assessed IP-10 levels in HIV infected and HIV uninfected patients and found that among 65 HIV uninfected active TB patients, IP-10 levels at diagnosis and at 2-4, 6-12 and 12-24 weeks of anti-TB chemotherapy showed significant decrease in IP-10 levels after 12-24 weeks [20]. In our study there was no significant decrease in IP-10 levels at diagnosis and after 2 months of treatment. There was no association of IP-10 with GeneXpert and no significant difference in IP-10 levels was found in relation to sputum grading and X-ray score at diagnosis and after 2 months of treatment. Previous studies have shown significant decrease in IP-10 levels at end of treatment with only one study showing significant decline starting at 2 weeks. Thus, IP-10 does not appear to have role in the initial follow up of PTB patients.

\section{Conclusions}

IP-10 seemed to have very limited role in diagnosis of active TB especially in countries with high prevalence of LTBI. Our study could not establish the place of IP-10 in follow up of PTB patients. However, more studies are needed in this pretext with larger sample size and extended duration of follow up.

\section{References}

1. World Health Organization. Global tuberculosis report 2020. Available from: https://www.who.int/publications/i/item/ 9789240013131

2. Khusro A, Aarti C, Salem AZM. An overview on the current status of tuberculosis and its biomarkers. J Biol Chemistry 2000;275:28326-31.

3. Nguyen TNA, Anton-Le Berre V, Bañuls A-L, Nguyen TVA. Molecular diagnosis of drug-resistant tuberculosis; A literature review. Front Microbiol 2019;10:794.

4. El-emiry FA, Attia GA, Ahmad AY, Sakr BM. Diagnostic value of inducible protein-10 in pulmonary tuberculosis. Egypt J Chest Dis Tubercul 2016;65:219-25.

5. Hong JY, Jung GS, Kim H, et al. Efficacy of inducible protein 10 as a biomarker for the diagnosis of tuberculosis. Int J Infect Dis 2012;16:e855-9.

6. Kabeer BSA, Raman B, Thomas A, et al. Role of Quanti FERON-TB gold, interferon gamma inducible protein-10 and tuberculin skin test in active tuberculosis diagnosis. PLoS One 2010;5:e9051.
7. Central TB Division, Directorate General of Health Services, Ministry of Health with Family Welfare. National strategic plan for tuberculosis elimination 2017-2025. Accessed: 2020 Jul 15. Available from: https://bcindia.gov.in/WriteReadData/ NSP\%20Draft \%2020.02.2017\%201.pdf

8. World Health Organization. The use of lateral flow urine lipoarabinomannan assay (LF-LAM) for the diagnosis and screening of active tuberculosis in people living with HIV. Available from: http://www.who.int/tb/publications/use-of-lflam-tb-hiv/en/

9. Ruhwald M, Aabye MG, Ravn P. IP-10 release assays in the diagnosis of tuberculosis infection: current status and future directions. Expert Rev Mol Diagn 2012;12:175-87.

10. Dufour JH, Dziejman M, Liu MT, et al. IFN-gamma-inducible protein 10 (IP-10; CXCL10)-deficient mice reveal a role for IP-10 in effector $\mathrm{T}$ cell generation and trafficking. J Immunol 2002;168:3195-204.

11. Lee J, Lee J-Y, Choi H-H, et al. Elevated levels of interferoninducible protein 10 (IP)-10/CXCL10, but not of interferon- $\gamma$, in patients with pulmonary tuberculosis. J Bacteriol Virol 2007;37:137-46.

12. Qiu X, Tang Y, Yue Y, et al. Accuracy of interferon- $\gamma$-induced protein 10 for diagnosing latent tuberculosis infection: a systematic review and meta-analysis. Clin Microbiol Infect 2019;25:667-72.

13. Qiu X, Xiong T, Su X, et al. Accumulate evidence for IP-10 in diagnosing pulmonary tuberculosis. BMC Infect Dis 2019;19:924.

14. Qiu X, Tang Y, Zou R, et al. Diagnostic accuracy of interferongamma-induced protein 10 for differentiating active tuberculosis from latent tuberculosis: A meta-analysis. Sci Rep 2019;9:11408.

15. Aabye MG, Ruhwald M, Praygod G, et al. Potential of interferon- $\gamma$-inducible protein 10 in improving tuberculosis diagnosis in HIV-infected patients. Eur Respir J 2010;36:1488-90.

16. Petrone L, Cannas A, Aloi F, Nsubuga M, Sserumkuma J, Nazziwa RA, et al. Blood or urine IP-10 cannot discriminate between active tuberculosis and respiratory diseases different from tuberculosis in children. Biomed Res Int 2015;2015:589471.

17. Whittaker E, Gordon A, Kampmann B. Is IP-10 a better biomarker for active and latent tuberculosis in children than IFNgamma? PLoS One 2008;3:e3901.

18. Tonby K, Ruhwald M, Kvale D, Dyrhol-Riise AM. IP-10 measured by dry plasma spots as biomarker for therapy responses in Mycobacterium tuberculosis infection. Sci Rep 2015;5:9223.

19. Azzurri A, Sow OY, Amedei A, et al. IFN-gamma-inducible protein 10 and pentraxin 3 plasma levels are tools for monitoring inflammation and disease activity in Mycobacterium tuberculosis infection. Microbes Infect 2005;7:1-8.

20. Wergeland I, Pullar N, Assmus J, et al. IP-10 differentiates between active and latent tuberculosis irrespective of HIV status and declines during therapy. J Infect 2015;70:381-91.

21. Kobashi Y, MouriK, Kato S, Oka M. Clinical evaluation of IP10 and MIG for the diagnosis of active tuberculosis disease. Mycobact Dis 2015;5:1000185.

22. Jeong YH, Hur Y-G, Lee H, et al. Discrimination between active and latent tuberculosis based on ratio of antigen-specific to mitogen-induced IP-10 production. J Clin Microbiol 2015;53:504-10. 